\title{
Article
}

\section{Quantifying the Temperature of Maggot Masses and its Relationship to Decomposition}

Heaton, Vivienne, Moffatt, Colin and Simmons, Tal Linda lleen Available at http://clok.uclan.ac.uk/9321/

Heaton, Vivienne, Moffatt, Colin and Simmons, Tal Linda Ileen (2014) Quantifying the Temperature of Maggot Masses and its Relationship to Decomposition. Journal of Forensic Sciences, 59 (3). pp. 676-682. ISSN 00221198

It is advisable to refer to the publisher's version if you intend to cite from the work. http://dx.doi.org/10.1111/1556-4029.12396

For more information about UCLan's research in this area go to http://www.uclan.ac.uk/researchgroups/ and search for <name of research Group>.

For information about Research generally at UCLan please go to http://www.uclan.ac.uk/research/

All outputs in CLoK are protected by Intellectual Property Rights law, including Copyright law. Copyright, IPR and Moral Rights for the works on this site are retained by the individual authors and/or other copyright owners. Terms and conditions for use of this material are defined in the policies page.

\section{CLoK}

Central Lancashire online Knowledge www.clok.uclan.ac.uk

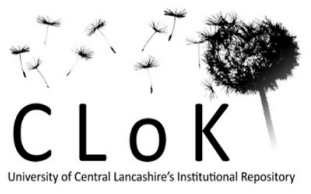




\section{Elsevier Editorial System(tm) for Forensic Science International Manuscript Draft}

Manuscript Number: FSI-D-12-00140R1

Title: Quantifying the Temperature of Maggot Masses and its Relationship to Decomposition

Article Type: Original Research Paper

Keywords: Forensic science; forensic entomology; blowflies; maggot masses; temperature; postmortem interval

Corresponding Author: Dr Tal Simmons, PhD

Corresponding Author's Institution: University of Central Lancashire

First Author: Tal Simmons, PhD

Order of Authors: Tal Simmons, PhD; Vivienne Heaton, BSc, MSc; Moffatt Colin, PhD

Abstract: Observed to arrive at a body within minutes of death, blowflies are frequently used as a biological clock in criminal investigations, aiding in the estimation of the post-mortem interval (PMI). In forensic entomology, PMI is thus calculated based on the time it takes the larvae recovered from decomposed remains to complete their developmental cycle at a constant ambient temperature under controlled laboratory conditions. However, very few studies take into consideration the mass generated heat produced by larvae co-existing in an aggregation. This study investigates the correlation between the number of blowfly larvae in a maggot mass and the amount of heat generated, as well as identifying the minimum mass size and elapsed time before any differences in accrued temperature achieve significance. Various sized larval masses composed solely of Lucilia sericata were reared in the laboratory at a constant ambient temperature of $22^{\circ} \mathrm{C}$. Data loggers were used to record temperatures inside the maggot masses at five minute intervals for the duration of the feeding stage of development. Results showed a strong positive relationship between mass size and the amount of internally generated heat. A minimum mass size of 1200 individuals was required for the microclimate temperature to increase significantly above ambient, with aggregations composed of 2500 larvae producing temperatures that exceeded ambient by as much as $14^{\circ} \mathrm{C}$. Comparing accumulated degree hours (ADH) for different sized masses at specific times during development highlighted 26 hours as the point at which the 1200 masses became significantly warmer than ambient. Larger masses had $\mathrm{ADH}$ values that diverged from ambient after as little as ten hours into feeding and development. Larvae developing in a mass were also observed to experience two peaks in temperature, one as they progressed from 2 nd instar to 3rd instar, and another immediately prior to them entering the postfeeding phase of development. If these localized amplifications in temperature exceed the upper developmental threshold for a species, then larval growth may be disrupted. As a consequence of this, underdeveloped larvae could be mistakenly identified as smaller, younger individuals, which would result in the PMI being underestimated.

Suggested Reviewers: 
Quantifying the Temperature of Maggot Masses and its Relationship to Decomposition

Vivienne Heaton, M.Sc.; Colin Moffatt, Ph.D.; and Tal Simmons, Ph.D.

School of Forensic and Investigative Sciences

University of Central Lancashire

Preston, PR1 2HE

UK 


\section{ABSTRACT}

Observed to arrive at a body within minutes of death, blowflies are frequently used as a biological clock in criminal investigations, aiding in the estimation of the post-mortem interval (PMI). In forensic entomology, $\mathrm{PMI}$ is thus calculated based on the time it takes the larvae recovered from decomposed remains to complete their developmental cycle at a constant ambient temperature under controlled laboratory conditions. However, very few studies take into consideration the mass generated heat produced by larvae co-existing in an aggregation. This study investigates the correlation between the number of blowfly larvae in a maggot mass and the amount of heat generated, as well as identifying the minimum mass size and elapsed time before any differences in accrued temperature achieve significance. Various sized larval masses composed solely of Lucilia sericata were reared in the laboratory at a constant ambient temperature of $22^{\circ} \mathrm{C}$. Data loggers were used to record temperatures inside the maggot masses at five minute intervals for the duration of the feeding stage of development. Results showed a strong positive relationship between mass size and the amount of internally generated heat. A minimum mass size of 1200 individuals was required for the microclimate temperature to increase significantly above ambient, with aggregations composed of 2500 larvae producing temperatures that exceeded ambient by as much as $14^{\circ} \mathrm{C}$. Comparing accumulated degree hours (ADH) for different sized masses at specific times during development highlighted 26 hours as the point at which the 1200 masses became significantly warmer than ambient. Larger masses had $A D H$ values that diverged from ambient after as little as ten hours into feeding and development. Larvae developing in a mass were also observed to experience two peaks in temperature, one as they progressed from $2^{\text {nd }}$ instar to $3^{\text {rd }}$ instar, and another immediately 
prior to them entering the post-feeding phase of development. If these localized amplifications in temperature exceed the upper developmental threshold for a species, then larval growth may be disrupted. As a consequence of this, underdeveloped larvae could be mistakenly identified as smaller, younger individuals, which would result in the PMI being underestimated.

Keywords: Forensic science, forensic entomology, blowflies, maggot masses, temperature, post-mortem interval

\section{ACKNOWLEDGEMENTS}

Thanks are extended to Livesey's Butchers, Preston, for supplying the pork liver and lamb ribs, as well as Ted Carter and Wayne's Tackle for providing the initial larval stock. We would also like to acknowledge Peter Cross and Naadia Bobat for helping to maintain fly colonies in the laboratory. 


\section{INTRODUCTION}

Calliphoridae, or blowflies, are recognised within the forensic community as a valuable source of evidence in criminal investigations owing to their predictable behaviour and worldwide distribution $[1,2]$. With some species arriving at a corpse within minutes of death $[3,4,5]$, their much studied development at controlled temperatures has allowed forensic entomologists to utilise them as a biological clock when estimating the post mortem interval (PMI) $[5,6,7,8,9,10,11,12,13]$.

Eggs laid on a suitable ephemeral resource such as a corpse will hatch after between six and 40 hours, depending on environmental conditions and species [1]. These minute larvae will then proceed to feed and develop through three stages known as instars, becoming progressively larger. The general rule amongst forensic entomologists calculating larval age is that the largest individual collected from a corpse is the oldest and most likely to have developed from the first eggs laid. But there are a number of complicating factors, not least the fact that larvae undergo a rapid reduction in body length once they enter the post feeding stage of development $[14,15]$.

Mature blowflies and their larvae are poikilothermic, meaning body temperature is governed by the ambient temperature, and the warmer the conditions, the faster the metabolic rate and hence the faster the rate of development $[8,13,14,16,17,18,19,20]$. Each blowfly population has a particular temperature range wherein successful larval development can occur, and this may differ amongst taxa and geographical location [21]. 
Development is fastest around the centre of this range, but ceases outside it, in some cases killing the insect $[9,13,20,22,23,24]$.

As larvae develop and reach their $2^{\text {nd }}$ instar, they usually aggregate into a maggot mass: an assemblage of feeding larvae in which metabolic heat increases the localised temperature above ambient $[4,25]$. A mass is beneficial for larvae since it maximises their feeding efficiency by producing sufficient proteolytic enzymes for tissue breakdown $[23,26,27,28$, 29]. As larvae in a mass are in a constant state of motion, friction from their bodies repeatedly rubbing against one another, combined with their rapid metabolism, results in a sudden and localized increase in temperature, often reaching highs of $27-35^{\circ} \mathrm{C}$ [30]. These optimum temperatures provide protection from any sudden and temporary drops in ambient and allow larvae to preserve their own stable environment for accelerated development, even when stored at lows of $4^{\circ} \mathrm{C}[5,18,23,31]$. But these temperatures can only be maintained if aggregations exceed a minimum volume, the general rule being that the larger the mass, the greater the amount of heat produced [21, 32, 33]. However, there are cases where large masses have reportedly generated temperatures approaching highs of $50^{\circ} \mathrm{C}[1,5,23,32]$. These extreme temperatures lie well above the upper lethal limit for blowfly larvae $[9,10,13]$ and one would expect highs such as this to result in increased larval mortality, and at the very least to inhibit development.

Despite the fact that heat generated by a maggot mass is often highlighted in the literature as a significant influence on the larval development rates $[1,5,7,18,26,28,31,32,33]$, it 
has very rarely been taken into consideration when estimating the post mortem interval. Mass generated heat could affect larval development and any subsequent PMI estimates in two very different ways. Firstly, if the mass increases the local temperature to an optimum level, then the rate of larval development may increase. With individuals becoming larger sooner, entomologists may mistake them for older larvae. This could lead to an overestimation of the post-mortem interval. But in cases involving human cadavers, the opposite could be true. If the larger masses found on these corpses [34, 35, 36, 37] are generating temperatures above the upper limit and hindering development, then the affected larvae may be smaller than expected for their age. If these underdeveloped individuals are mistaken for younger larvae then this might lead to an underestimation in the PMI. Either way, this could have serious implications for criminal investigations.

The aim of this study was to investigate whether the number of larvae in a maggot mass influences the amount of heat generated locally. By identifying the smallest mass size capable of producing a microclimate significantly warmer than ambient, it should be possible to highlight cases where mass generated heat is a factor that may need to be considered in PMI estimates. It is hoped that this will eventually lead towards increasing accuracy when relying on larval development for PMI estimates in criminal investigations. 


\section{MATERIALS AND METHODS}

Blowfly eggs were harvested from a laboratory reared colony of Lucilia sericata (Phaenicia sericata in North America), which originated from larval stock purchased from a local fishing tackle outlet. L. sericata were used for this investigation since they have a well-studied lifecycle, a global distribution and are commonly located in close proximity to human habitats, which often gives them immediate access to corpses; important characteristics to aid in criminal investigations $[38,39,40]$.

Pork liver was introduced into cages housing mature blowflies to stimulate oviposition. Once eggs were harvested they were kept in an incubator with $60 \% \mathrm{RH}$, a constant temperature of $22^{\circ} \mathrm{C}$ and a $16: 8 \mathrm{~h}(\mathrm{~L}: \mathrm{D})$ photoperiod. The light source in the incubator was supplied by standard 40W fluorescent tubes emitting white light. Eggs were monitored until $1^{\text {st }}$ instar larvae hatched after approximately $24-36$ hours. These $1^{\text {st }}$ instar larvae were then counted out and randomly allocated to different sized masses $(50,100,150,200,300,600$, $900,1200,1500,1800$ and 2500 ) before being placed directly onto racks of lamb ribs. Racks of lamb ribs were used for this study, as they were readily available from a local butcher and provided ample food for even the largest experimental masses, allowing them to complete development without facilitating competition, which can reportedly influence mass temperature $[1,4,6]$. The meat and larvae were then stored in 10 l plastic containers measuring $27 \times 27 \times 16 \mathrm{~cm}$ and placed back in the incubator at a constant temperature of $22^{\circ} \mathrm{C}$, within the optimum range for this species where maximum heat emission is promoted [33], for the duration of the experiment. 
Using data loggers, maggot mass temperatures were recorded every five minutes from the start of the experiment and were verified using a FLIR T425 thermal imaging camera (FLIR Systems Ltd (UK), 2 Kings Hill Avenue, West Malling, Kent, ME19 4AQ UK). Thermocouples with data loggers were also used to take readings at five minute intervals inside the incubator to ensure the ambient temperature remained constant. Once larvae entered the post feeding stage of development and began to migrate away from the food source dispersing the mass, data collection ceased. This usually occurred between $40-48$ hours into the experiment and was easily identifiable as migrating larvae were observed escaping sealed containers and incubators with ease. For each of the eleven mass sizes there were three repeats, plus three controls, giving a total of 36 sets of recorded data. Controls for the experiments consisted of ribs with no larvae and were used to represent rib temperature minus larval activity during data analysis.

\section{Statistical Analysis}

For each of the 36 experiments, the first two hours of temperature data were discarded, allowing time for both the refrigerated racks of lamb ribs to adjust to ambient and for larvae to recover from any physical disturbance experienced in the initial stages of the experiment. The remaining data were then analysed using the statistical package $R$ [41]. A repeated measures ANOVA was carried out to compare overall temperature in the different mass sizes between the times of 120 and 2880 minutes. The results of this analysis were investigated further with a multiple comparison of means test, used to identify which 
masses produced similar or significantly different temperatures. Peak temperatures recorded for each of the 36 experimental masses were examined using linear regression. This was used to determine whether there was a relationship between mass size and the maximum temperature produced as well as identify whether a regression equation could be used to estimate peak temperature based on mass size or vice versa. Using the recorded temperature data it was also possible to calculate accumulated degree hours (ADH) for each of the masses. An ANOVA followed by post-hoc multiple comparison of means using Tukey's Test were used on these data to highlight which masses have significantly different $A D H$ values at specific times during development, with subsets being taken at five hour intervals. Diagnostic plots showed the data to be normally distributed and of uniform variance in every case.

\section{RESULTS}

\section{Initial Observations}

Condensation was observed on the inside of the plastic containers housing the larger masses (1200+ individuals) along with a substantial amount of liquefied tissue accumulating in the vicinity of the aggregation. Individual larvae appeared more active and frenzied in these masses and on a number of occasions large aggregations of 1800 larvae or more were observed to separate into two smaller masses. Smaller aggregations remained as a single unit and displayed less frenzied behaviour, whilst the conditions produced inside their containers were considerably drier. Masses of all sizes were observed to move around the food source as a single entity and showed preference for more sheltered areas such as the 
underside of the meat. Larvae entered the migratory phase of development approximately 40-48 hours into the experiment, with larger masses completing development at the earlier end of the scale.

\section{Maggot Mass Temperatures}

Recorded temperatures taken from within the mass ranged from $20.5^{\circ} \mathrm{C}\left(1.5^{\circ} \mathrm{C}\right.$ below ambient) to $36^{\circ} \mathrm{C}\left(14^{\circ} \mathrm{C}\right.$ above ambient). Figure 1 clearly illustrates that as the larvae in the masses developed they were capable of generating heat greater than ambient, with temperature increasing in conjunction with mass size. However, this increase in temperature was not a gradual and constant process with the highest temperatures being recorded at the end of feeding when larvae were at their largest. Instead, temperatures were observed to rise and fall throughout development producing two distinct temperature peaks. During the initial hours of development all masses, regardless of their size, showed temperatures that were not only similar to each other, but also to ambient. For the first ca. 500 minutes temperatures increased gradually before reaching a plateau and remaining constant for a further $c a$. 500 minutes. After this point mass temperatures began to become more variable. Larval masses became progressively warmer as development advanced, with larger masses (1200+ larvae) showing more exaggerated increases. However, despite the 2500 mass peaking at approximately $36^{\circ} \mathrm{C}$, several degrees higher than the 1800 mass, its temperature curve was initially shallower in comparison. This indicates a slower rate of temperature increase. After peaking, temperatures dropped, but were maintained several degrees above ambient for the duration of the experiment until 
masses experienced a second, smaller peak just prior to the migratory stage of development.

Analysis of the data showed that there were significant differences between masses of different size and the temperatures they produce, with larger masses producing higher temperatures $\left(F_{11,24}=12.74, p\right.$-value $\left.<0.0001\right)$. Again, using the control group to represent ambient, the results showed that smaller masses (50-900 individuals) produced temperatures that were similar to one another as well as to ambient (Table 1). Larger masses composed of 1200 larvae or more produced temperatures significantly higher than ambient as well as the majority of the smaller masses. However, despite larger masses producing more heat than ambient, they failed to be significantly warmer than masses of a similar size. For example, the 2500 mass was not significantly warmer than the 1800,1500 or 1200 masses whilst the 1200 mass was only warmer than the control and the masses of 50, 100 and 150 larvae. This suggests that when comparing the thermal output in two aggregations, there needs to be a difference in mass size of approximately 1000 larvae or more for those temperature readings to differ significantly.

\section{Peak Temperatures}

Peak temperatures recorded for each of the 36 experimental masses ranged from $23.5^{\circ} \mathrm{C}$ in the control experiments to $36^{\circ} \mathrm{C}$ in the 2500 masses. All temperature peaks occurred after 1200 minutes ( 20 hours) had elapsed. Figure 2 displays the data points and regression line 
for peak temperature against mass size. The regression line through the points produced the simple regression equation of:

$$
\text { PEAK }=23.8+0.0046 \mathrm{MASS}
$$

This model fits the data well $\left(r^{2}=0.95, F_{1,34}=684.9, p\right.$-value $\left.<0.001\right)$ and shows that there was a strong positive relationship between the recorded maximum temperature and the size of the maggot mass, with the peak temperature increasing by $0.46^{\circ} \mathrm{C}$ for every 100 larvae added. $95 \%$ of the peak temperature recorded in a mass is accounted for by the size of that aggregation.

\section{Accumulated Degree Hours (ADH)}

At 10 hours into development the first differences in $A D H$ values were observed $\left(F_{11}\right.$, $24=2.44, p$-value $=0.033$ ) with the 1800 mass producing an $A D H$ value greater than ambient (Figure 3, A). As time progressed and ADH values increased, pairwise comparisons showed that an increasing number of masses began to produce $A D H$ values that differed from ambient as well as from each other. After 40 hours of feeding and development, maggot masses composed of 1200 larvae or more had significantly higher ADH values than ambient $\left(F_{11,24}=16.197, p\right.$-value $\left.<0.0001\right)$ (Figure $\left.3, C\right)$. Since no smaller masses were capable of producing $A D H$ values greater than ambient, 1200 becomes the critical mass size for heat production. 
Twenty-six hours were required before this critical mass was capable of producing ADH values greater than ambient ( $p$-value $=0.048)$. Larger masses composed of 1500,1800 and 2500 larvae had ADH values greater than ambient after 19, 10 and 22 hours respectively. Despite the 2500 masses producing the maximum recorded temperatures, the amount of time required for them to accumulate heat energy, as reflected in the ADH values, was longer in comparison to smaller masses. Aggregations composed of 1500 and 1800 individuals may not have reached as high a temperature as the 2500 masses, but they were capable of producing $A D H$ values significantly greater than ambient several hours earlier. This was also reflected in the temperature graph (Figure 1) with the 2500 curve appearing shallower in comparison during the first half of the experiment, representing a more gradual increase in temperature.

\section{DISCUSSION}

The two temperature peaks recorded in the maggot masses are believed to represent a particular stage of larval development. The first and most prominent peak identifies the point at which $2^{\text {nd }}$ instar larvae metamorphose into larger $3^{\text {rd }}$ instar larvae, whilst the second, smaller, peak occurs just prior to the larvae entering the post-feeding migration phase of development. Increases in temperature at these points can be explained by the increased energy demands required by larvae to pass through these junctures. Moulting from one instar to the next as well as migrating away from a corpse in search of a suitable site to pupate are both energetically expensive stages of development. To ensure they successfully progress through these stages, larvae display more frenzied feeding behaviour, filling their crops within 2-3 minutes [29]. Thus, larvae in this experiment are seen to 
increase their basal metabolic rate (reflected in peak heat output) as a means of accumulating and/or storing energy necessary to undertake transition through these phases. As a consequence of this the mass experiences a sudden and localized increase in temperature.

The graph of the linear regression successfully demonstrates the strong positive relationship between the size of the mass and its peak temperature. However, the plotted data points and their associated regression line suggest that, as mass size increases, temperature increases indefinitely with no signs of reaching a maximum level. In reality, this is highly unlikely, especially in large masses similar to those found on cadavers. Temperatures inside a mass can only increase so far. Above the upper lethal limit larvae would be effectively killing themselves with thermal stress. The regression equation proposed in this study is therefore useful in estimating peak temperature or mass size in smaller laboratory based aggregations, but less so for larger masses out in the field. To be able to use linear regression on criminal cases with confidence, more research needs to be carried out on a larger scale and under field conditions with varying ambient temperatures. These studies would enable investigators to substitute larval numbers with mass weight or volume as well as highlight the point at which temperatures begin to plateau.

The 2500 mass may be taking longer to accrue heat in comparison to smaller masses as a result of its larvae altering their behaviour to adapt to an increasingly stressful thermal environment. Lucilia sericata are reported to have an upper lethal limit of approximately 
$35^{\circ} \mathrm{C}[33,42]$, which coincides with the maximum temperature recorded in the 2500 mass. If larvae are able to identify the presence of a large number of individuals, this may trigger some form of thermoregulatory behaviour during the initial stages of mass formation when larvae are at their most vulnerable. This early recognition of a potential problem would allow larvae to alter their behaviour accordingly and take control of their microclimate, preventing temperatures becoming too high too soon. By repeatedly moving from the feeding centre of the mass, where temperatures are highest, to the cooler periphery larvae are able to prevent overheating, but at the expense of the amount of time spent feeding. Although unable to stop the inevitable increase in temperature, they have slowed it down. Thermoregulation may also explain the observed splitting of large masses into two smaller masses, another behavioural adaptation perhaps used to avoid critically high temperatures. The fact that the 1800 masses diverged from ambient so early in development (after as little as 10 hours) suggests that this may be the optimum mass size for L. sericata. Peaking at approximately $30^{\circ} \mathrm{C}$, several degrees below the lethal limit, they were able to produce and maintain temperatures greater than all the other masses throughout $1^{\text {st }}$ and $2^{\text {nd }}$ instar development. This indicates that larvae in these masses are able to feed uninhibited in optimum conditions without having to invest valuable time carrying out temperature avoidance behaviours, since they do not have the capacity to reach the critical temperature.

Internally generated heat in larval aggregations has the potential to impact very significantly on PMI estimates. If the high temperatures produced by larval masses are disrupting feeding and development, then older larvae will be smaller and hence appear younger than they actually are. The problem then arises when these underdeveloped larvae are 
compared to laboratory reared larvae and aged without taking into account the mass size or the heat that was generated. This could result in an underestimation when calculating the PMI. Conversely, if the size of the larval mass falls within the optimum range and produces a microclimate more favoured for feeding, then the rate of development may increase and larvae will appear larger, and hence older, sooner than expected. This could then lead to an overestimation of the PMI. These optimum conditions provided by the microclimate could also result in larvae entering the migratory phase of development earlier than expected which may result in evidence being overlooked at a crime scene. When larvae are collected as evidence in a criminal investigation, it is often the largest which are targeted for PMI estimates as it is believed these are the oldest and most developed individuals, hatched from the first batch of eggs. However, this may not always be the case. Larvae in the postfeeding stages of development may have already undergone a reduction in length, but still be in the vicinity of the corpse and be mistaken for younger, smaller larvae. This could lead to further errors in PMI estimates.

This investigation has shown that even small larval masses of approximately 1200 individuals are capable of producing a level of heat significantly greater than ambient after as little as 26 hours. It would be safe to assume therefore that any mass comprised of more than 1200 larvae that has been developing for at least 26 hours is producing a significant amount of heat that may be affecting development of larvae within that mass. This could have consequences for the field of forensic entomology, not just at the crime scene, during the collection of larvae, but also in the laboratory. Very rarely is mass size or volume recorded or even mentioned in reports investigating the use of larval growth and 
development for PMI estimates $[34,35,36,43]$. If the methods used to calculate larval age are derived from studies where individuals were reared in a mass then, depending on the mass size and its potential for heat generation, what we believe to be a "standard" rate of development could actually be non-normative. To avoid any potential inaccuracies in PMI estimates based on larval development it may be necessary to produce a set of standards for the laboratory which factors in mass size. This would ensure that future studies are controlling for the temperature variable, resulting in more consistent developmental data being produced. Further investigations are encouraged to investigate what kind of effect, if any, these mass temperatures have on larval behaviour and development and whether or not it is a variable that should be factored into PMI estimates.

\section{CONCLUSIONS}

As larval masses increase in size the amount of heat they produce internally also increases with masses containing 1200 larvae or more producing temperatures that are significantly warmer than ambient. These temperature differences begin to appear after as little as 10 hours with all masses generating excess heat after 26 hours. The microclimate of a maggot mass has the potential to impact hugely on any PMI estimates that are based on larval development. Further research is encouraged in this area to ascertain whether or not mass temperature is a factor which needs to be incorporated into calculations that age larvae. This could therefore increase accuracy when estimating the post-mortem interval in criminal investigations. 


\section{REFERENCES}

1. C.P. Campobasso, G. Di Vella, F. Introna, Factors affecting decomposition and Diptera colonization, Forensic Sci. Int. 120 (2001) 18-27.

2. V.K. Kashyap, V.V. Pillay, Efficacy of entomological method in estimation of postmortem interval: A comparative analysis, Forensic Sci. Int. 40 (1989) 245-250.

3. W.C. Rodriguez, W.M. Bass, Insect activity and its relationship to decay rates of human cadavers in East Tennessee, J. Forensic Sci. 23 (1983) 423-432.

4. B.S. Shean, L. Messinger, M. Papworth, Observations of differential decomposition on sun exposed v. shaded pig carrion in coastal Washington State, J. Forensic Sci. 38 (1993) 938-949.

5. M.I. Marhenko, Medicolegal relevance of cadaver entomofauna for the determination of time of death, Forensic Sci. Int. 120 (2001) 89-109.

6. C.P. Campobasso, F. Introna, The forensic entomologist in the context of the forensic pathologist's role, Forensic Sci. Int. 120 (2001) 132-139.

7. J. Amendt, C.S. Richards, C.P. Campobasso, R. Zehner, M.J.R. Hall, Forensic Entomology: Applications and Limitations, Forensic Sci. Med. Pathol. 7 (2010) 379392.

8. G.S. Anderson, Minimum and maximum development rates of some forensically important Calliphoridae (Diptera), J. Forensic Sci. 45 (2000) 824-832.

9. J.H. Byrd, J.C. Allen, The development of the black blow fly, Phormia regina (Meigen), Forensic Sci. Int. 120 (2001) 79-88. 
10. S.E. Donovan, M.J.R. Hall, B.D. Turner, C.B. Moncrieff, Larval growth rates of the blowfly, Calliphora vicina, over a range of temperatures, Med. Vet. Entomol. 20 (2006) 106-114.

11. M. Grassberger, C. Reiter, Effect of temperature on Lucilia sericata (Diptera: Calliphoridae) development with special reference to the isomegalen- and isomorphen-diagram, Forensic Sci. Int. 120 (2001) 32-36.

12. M. Grassberger, C. Reiter, Effect of temperature on development of Liopygia ( Sarcophaga) argyrostoma (Robineau-Desvoidy) (Diptera: Sarcophagidae) and its forensic implications, J. Forensic Sci. 47 (2002) 1-5.

13. P.D. Nabity, L.G. Higley, T.M. Heng-Moss, Effects of temperature on development of Phormia regina (Diptera: Calliphoridae) and use of developmental data in determining time intervals in forensic entomology, J. Med. Entomol. 43 (2006) $1276-1286$.

14. J.H. Byrd, J.F. Butler, Effects of temperature on Chrysomya rufifacies (Diptera: Calliphoridae) development, J. Med. Entomol. 34 (1997) 353-358.

15. L. Gomes, C.J. Von Zuben, Postfeeding radial dispersal in larvae of Chrysomya albiceps (Diptera: Calliphoridae): implications for forensic entomology, Forensic Sci. Int. 155 (2005) 61-64.

16. S. Niederegger, J. Pastuschek, G. Mall, Preliminary studies of the influence of fluctuating temperatures on the development of various forensically relevant flies, Forensic Sci. Int. 199 (2010) 72-78.

17. S. Huckesfeld, S. Niederegger, P. Schlegel, H-G. Heinzel, R. Spieß, Feel the heat: The effect of temperature on development, behaviour and central pattern generation in 3rd instar Calliphora vicina larvae, J. Insect Physiol. 51 (2011) 136-146. 
18. E.P. Catts, Problems in estimating the post-mortem interval in death investigations, J. Agric. Entomol. 9 (1992) 245-255.

19. M. Grassberger, C. Reiter, Effect of temperature on development of the forensically important holarctic blow fly Protophormia terraenovae (Robineau-Desvoidy) (Diptera: Calliphoridae), Forensic Sci. Int. 128 (2002) 177-182.

20. C. Ames, B. Turner, Low temperature episodes in development of blowflies: implications for postmortem interval estimation, Med. Vet. Entomol. 17 (2003) 178-186.

21. M.B. Gallagher, S. Sandhu, R. Kimsey, Variation in developmental time for geographically distinct populations of the common green bottle fly, Lucilia sericata (Meigen)*, J. Forensic Sci. 55 (2010) 438-442.

22. J. Davidson, On the relationship between temperature and rate of development of insects at constant temperatures, J. Anim. Ecol. 13 (1944) 26-38.

23. C.S. Richards, B.W. Price, M.H. Villet, Thermal ecophysiology of seven carrionfeeding blowflies in Southern Africa, Entomol. Exp. Appl. 131 (2009) 11-19.

24. D.S. Saunders, S.A.L. Hayward, Geographical and diapause-related cold tolerance in the blow fly, Calliphora vicina, J. Insect Physiol. 44 (1998) 541-551.

25. J.H. Byrd, J.L. Castner, Forensic entomology: the utility of arthropods in legal investigations. Boca Raton: CRC Press LLC, 2001.

26. S. Ireland, B. Turner, The effects of larval crowding and food type on the size and development of the blowfly, Calliphora vomitoria, Forensic Sci. Int. 159 (2006) 175181.

27. R.P. Hobson, Studies on the nutrition of blowfly larvae. III. The liquefaction of muscle, J. Exp. Biol. 9 (1932) 359-365. 
28. J.R. Goodbrod, M.L. Goff, Effects of larval population density on rates of development and interactions between two species of Chrysomya (Diptera: Calliphoridae) in laboratory culture, J. Med. Entomol. 27 (1990) 338-343.

29. Schoofs, S. Niederegger, R. Spieß, From behavior to fictive feeding: Anatomy, innervation and activation pattern of pharyngeal muscles of Calliphora vicina 3rd instar larvae, J. Insect Physiol. 55 (2009) 218-230.

30. N.H Haskell, R.D. Hall, V.J. Cervenka, M.A. Clark, On the body: Insects' life stage presence and their postmortem artifacts., in: W. Haglund, M. Sorg (Eds.), Forensic Taphonomy: The Postmortem Fate of Human Remains, CRC Press, Boca Raton, 1997, pp. 415-448.

31. T.E. Huntington, L.G. Higley, F.P. Baxendale, Maggot development during morgue storage and its effect on estimating the post-mortem interval, J. Forensic Sci. 52 (2007) 453-458.

32. D.H. Slone, S.V. Gruner, Thermal regulation in larval aggregations of carrion-feeding blow flies (Diptera: Calliphoridae), J. Med. Entomol. 44 (2007) 516-523.

33. D. Charabidze, B. Bourel, D. Gosset, Larval-mass effect: Characterisation of heat emission by necrophageous blowflies (Diptera: Calliphoridae) larval aggregates, Forensic Sci. Int. 211 (2011) 61-66.

34. M.I. Arnaldos, M.D. Garcia, E. Romera, J.J. Presa, A. Luna, Estimation of postmortem interval in real cases based on experimentally obtained entomological evidence, Forensic Sci. int. 149 (2005) 57-65.

35. M. Benecke, Six forensic entomology cases: description and commentary. J. Forensic Sci. 43 (1998) 797-805. 
36. F. Introna, C.P. Campobasso, A. Di Fazio, Three case studies in forensic entomology from Southern Italy, J. Forensic Sci. 43 (1998) 210-214.

37. R.W. Mann, W.M. Bass, L. Meadows, Time since death and decomposition of the human body: Variables and observations in case and experimental field studies, J. Forensic Sci. 35 (1990) 103-111.

38. G.S. Anderson, Comparison of decomposition rates and faunal colonization of carrion in indoor and outdoor environments, J. Forensic Sci. 56 (2011) 136-142.

39. M. Grassberger, C. Frank, Initial study of arthropod succession on pig carrion in a Central European urban habitat, J. Med. Entomol. 41 (2004) 511-523.

40. S. Vanin, P. Tasinato, G. Ducolin, C. Terranova, S. Zancaner, M. Montisci, S.D. Ferrara, M. Turchetto, Use of Lucilia species for forensic investigations in Southern Europe, Forensic Sci. Int. 177 (2008) 37-41.

41. R Development Core Team (2010). R: A language and environment for statistical computing. R Foundation for Statistical Computing, Vienna, Austria. ISBN 3-90005107-0, URL http://www.R-project.org/.

42. R. Wall, K.M. Pitts, K.E. Smith, Pre-adult mortality in the blowfly Lucilia sericata, Med. Vet. Entomol. 15 (2001) 328-334.

43. T.W. Adair, Calliphora vicina (Diptera: Calliphoridae) collected from a human corpse above 3400m in elevation, J. Forensic Sci. 53 (2008) 1212-1213. 


\section{Figure Captions}

Fig 1- Mean mass temperatures $\left({ }^{\circ} \mathrm{C}\right)$ vs. time (mins) for each of the mass sizes that displayed temperatures differing from ambient (control).

Fig 2 - Recorded peak temperature $\left({ }^{\circ} \mathrm{C}\right)$ for each of the experimental masses plotted with its regression line and 95\% confidence intervals.

Fig 3 - ADH values for each mass size at (A) 10 hours, (B) 30 hours and (C) 40 hours with associated standard error bars. 


\section{Table Captions}

Table 1 - Comparison of temperatures between maggot masses of different size (** represents significantly different temperatures, N.S represents no significant differences between mass temperatures). 


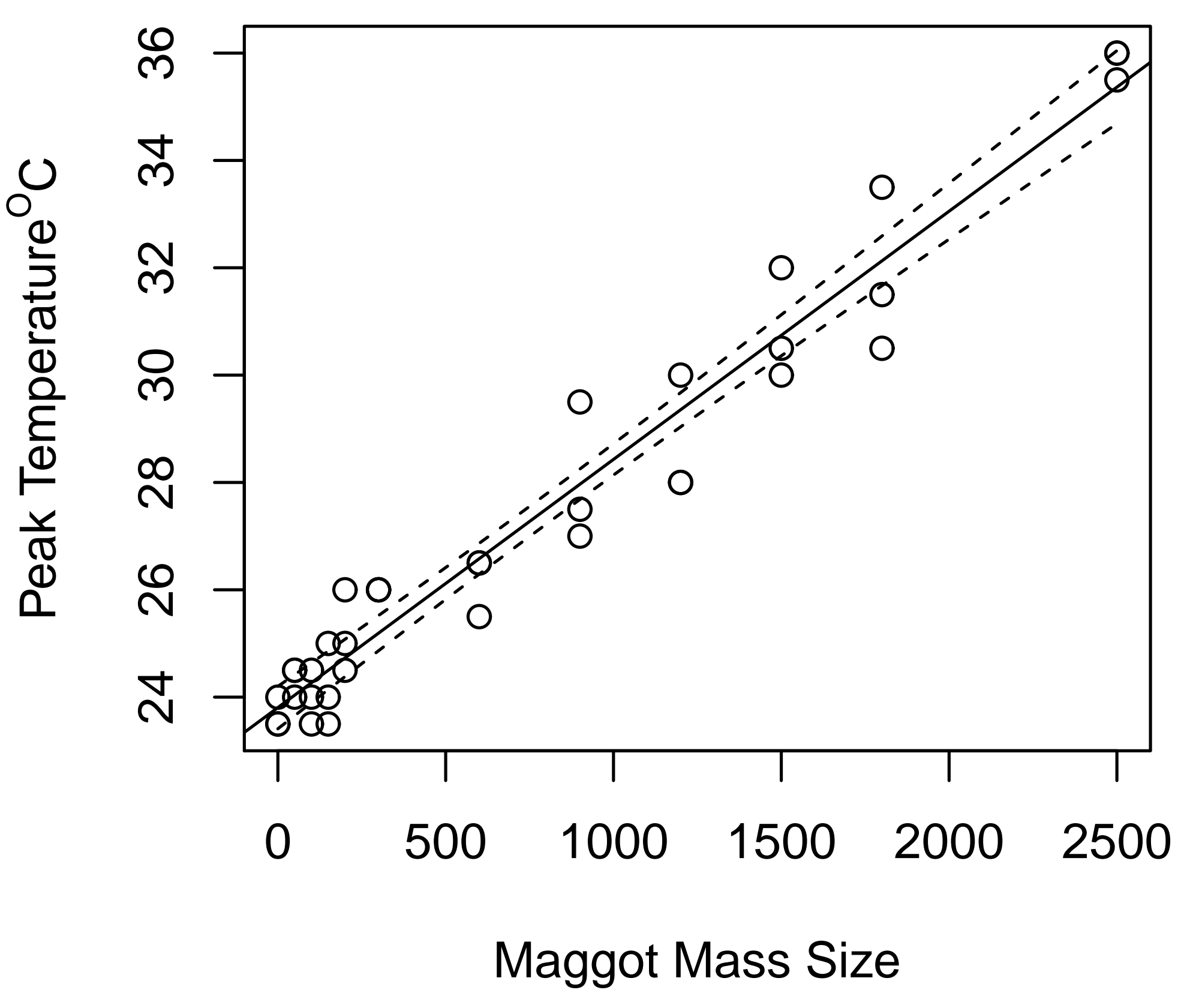

Maggot Mass Size

Figure 2

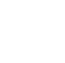

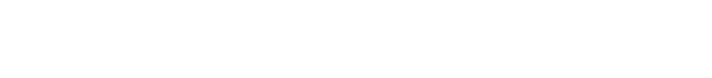




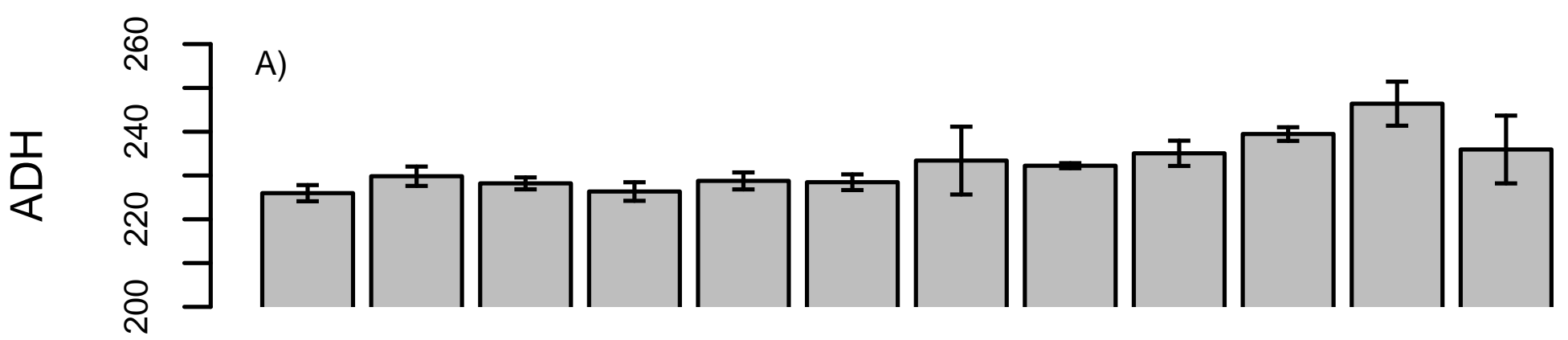
$\begin{array}{llllllllllll}\text { CTRL } & 50 & 100 & 150 & 200 & 300 & 600 & 900 & 1200 & 1500 & 1800 & 2500\end{array}$

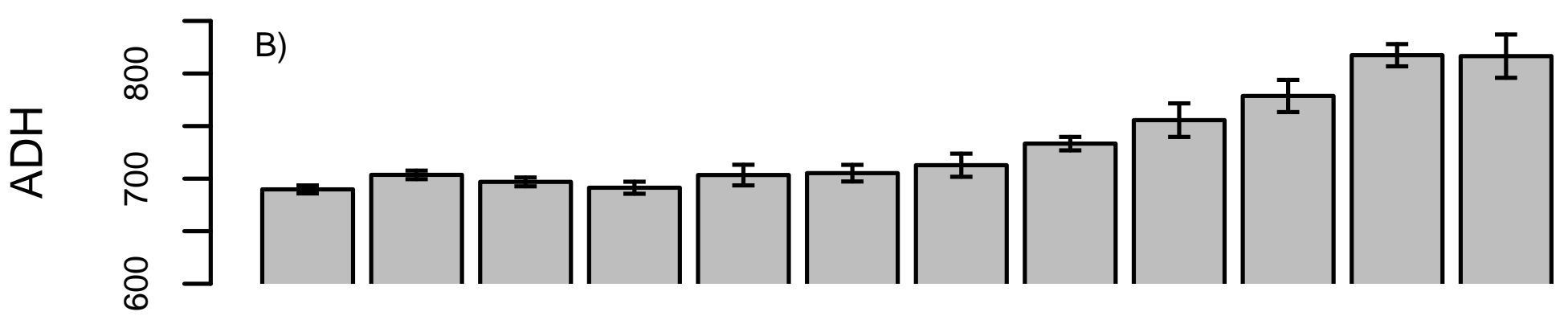
$\begin{array}{llllllllllll}\text { CTRL } & 50 & 100 & 150 & 200 & 300 & 600 & 900 & 1200 & 1500 & 1800 & 2500\end{array}$

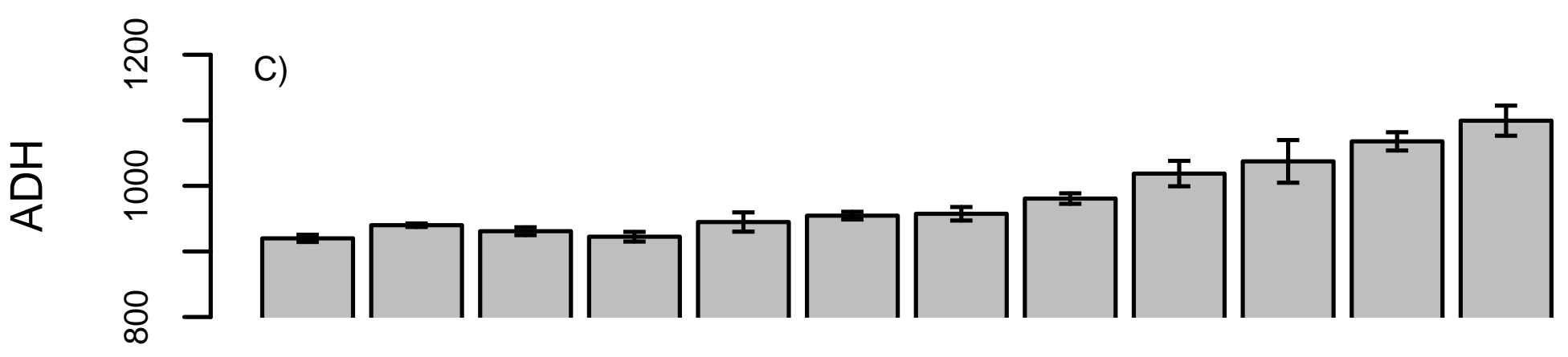
$\begin{array}{llllllllllll}\text { CTRL } & 50 & 100 & 150 & 200 & 300 & 600 & 900 & 1200 & 1500 & 1800 & 2500\end{array}$ 
Table1 - Comparison of temperatures between maggot masses of different size (** represents significantly different temperatures, N.S represents no significant differences between mass temperatures).

\begin{tabular}{|c|c|c|c|c|c|c|c|c|c|c|c|}
\hline & CTRL & 50 & 100 & 150 & 200 & 300 & 600 & 900 & 1200 & 1500 & 1800 \\
\hline 2500 & $* *$ & $* *$ & $* *$ & $* *$ & $* *$ & $* *$ & $* *$ & $* *$ & N.S & N.S & N.S \\
\hline 1800 & $* *$ & $* *$ & $* *$ & $* *$ & $* *$ & $* *$ & $* *$ & $* *$ & N.S & N.S & \\
\hline 1500 & $* *$ & $* *$ & $* *$ & $* *$ & $* *$ & $* *$ & N.S & N.S & N.S & & \\
\hline 1200 & $* *$ & $* *$ & $* *$ & $* *$ & N.S & N.S & N.S & N.S & & & \\
\hline 900 & N.S & N.S & N.S & N.S & N.S & N.S & N.S & & & & \\
\hline 600 & N.S & N.S & N.S & N.S & N.S & N.S & & & & & \\
\hline 300 & N.S & N.S & N.S & N.S & N.S & & & & & & \\
\hline 200 & N.S & N.S & N.S & N.S & & & & & & & \\
\hline 150 & N.S & N.S & N.S & & & & & & & & \\
\hline 100 & N.S & N.S & & & & & & & & & \\
\hline 50 & N.S & & & & & & & & & & \\
\hline
\end{tabular}




\section{Response to Reviewer Comments re. FSI-D-12-00140}

"Quantifying the Temperature of Maggot Masses and its Relationship to Decomposition"

\begin{tabular}{|c|c|}
\hline Reviewer 2's Comments & Response \\
\hline $\begin{array}{l}\text { Line } 12 \text { abstract - data loggers used to RECORD } \\
\text { temps... }\end{array}$ & $\begin{array}{l}\text { Abstract Line } 12 \text { - "recorded" amended to } \\
\text { "record" }\end{array}$ \\
\hline $\begin{array}{l}\text { Introduction, para } 4 \text {, line } 7-\text { I would re-word the } \\
\text { end of this sentence. As written it sounds like } 27- \\
35 \mathrm{C} \text { is the actual increase in temp rather than } \\
\text { the maximum recorded temp. }\end{array}$ & $\begin{array}{l}\text { Introduction, paragraph } 4 \text {, line } 7 \text { - changed from } \\
\text { "commonly in the range of } 27-35^{\circ} \mathrm{C} \text { " to "often } \\
\text { reaching highs of } 27-35^{\circ} \mathrm{C} \text { ". }\end{array}$ \\
\hline $\begin{array}{l}\text { Materials and Methods, para 2: Would it be } \\
\text { possible to describe (briefly) the light source } \\
\text { used to create the photoperiod and also maybe } \\
\text { the wavelength used. There have been reports } \\
\text { that certain wavelengths of light affect the } \\
\text { growth of insects and this (in theory) could have } \\
\text { affected your results. }\end{array}$ & $\begin{array}{l}\text { Materials and Methods, paragraph } 2 \text {, line } 3- \\
\text { included the sentence "The light source in the } \\
\text { incubator was supplied by standard } 40 \mathrm{~W} \\
\text { fluorescent tubes emitting white light." }\end{array}$ \\
\hline $\begin{array}{l}\text { Results - maggot mass temps - line } 26 . \text { The } \\
\text { sentence beginning with "However..." is } \\
\text { confusing and should be clarified or re-worded } \\
\text { (i.e. a mass of a mass with elevated masses?) }\end{array}$ & $\begin{array}{l}\text { Results, paragraph 2, line } 14 \text { - sentence changed } \\
\text { from "However, despite the mass of } 2500 \\
\text { individuals mass peaking at approximately } \\
36^{\circ} \mathrm{C} \text {, several degrees higher than the } 1800 \\
\text { mass, its temperature curve was initially } \\
\text { shallower in comparison, indicating a slower } \\
\text { rate of temperature increase" } \\
\text { to } \\
\text { "However, despite the } 2500 \text { mass peaking at } \\
\text { approximately } 36^{\circ} \mathrm{C} \text {, several degrees higher } \\
\text { than the } 1800 \text { mass, its temperature curve } \\
\text { was initially shallower in comparison. This } \\
\text { indicates a slower rate of temperature } \\
\text { increase." }\end{array}$ \\
\hline $\begin{array}{l}\text { Please change time since death to PMI } \\
\text { throughout the manuscript for consistency }\end{array}$ & Amended throughout the manuscript \\
\hline $\begin{array}{l}\text { Commas should precede the word "but" } \\
\text { throughout the manuscript - sorry about this } \\
\text { one, but I have to find something wrong. }\end{array}$ & Amended throughout the manuscript \\
\hline Reference 30 - taphonomy is misspelled & Reference 30 - spelling corrected \\
\hline $\begin{array}{l}\text { Results - ADH section. Even though the Figure } \\
\text { legend describes this, I would place the letter of } \\
\text { the graph next to the number of hours in the } \\
\text { text for clarity since hours and ADH are not the } \\
\text { same thing. ("At } 10 \text { hours (Figure } 1, \text { A)... }\end{array}$ & $\begin{array}{l}\text { Results, paragraph 6, line 3-“(Figure 3)" } \\
\text { amended to "(Figure 3, A) } \\
\text { Results, paragraph 6, line 7 - “(Figure 3)” } \\
\text { amended to "(Figure 3, C)" }\end{array}$ \\
\hline
\end{tabular}




\begin{tabular}{|l|l|}
\hline $\begin{array}{l}\text { Figure } 1 \text { caption - I would change the word } \\
\text { "against" }\end{array}$ & $\begin{array}{l}\text { This has been changed to "vs." - we cannot think } \\
\text { of any other suitable word }\end{array}$ \\
\hline $\begin{array}{l}\text { The results of the experiments carried out by the } \\
\text { Authors are very interesting and a correct } \\
\text { statistical approach has been used, despite } \\
\text { further improving can be done (it is not clear if a a } \\
\text { post hoc or a series of anova tests have been } \\
\text { performed). }\end{array}$ & $\begin{array}{l}\text { 'unplanned comparisons'. This means using a } \\
\text { test for multiple comparisons (usually Tukey) to } \\
\text { make comparisons between groups after the } \\
\text { ANOVA has shown you there are differences. } \\
\text { This is exactly what was used. The wording for } \\
\text { this section reads: } \\
\text { "An ANOVA followed by a multiple comparison of } \\
\text { means test was used on these data" }\end{array}$ \\
$\begin{array}{l}\text { Although we feel this is sufficient, we have } \\
\text { changed the wording slight to read : }\end{array}$ \\
$\begin{array}{l}\text { "An ANOVA followed by post-hoc multiple } \\
\text { comparison of means using Tukey's Test were } \\
\text { used..." }\end{array}$ \\
$\begin{array}{l}\text { The language is not "enough scientific", too } \\
\text { poor, with several not necessary sentences and } \\
\text { mistakes underlying a poor knowledge of the } \\
\text { Insect Nomenclature and Physiology (eg.: } \\
\text { "development is fastes around the center of this } \\
\text { range.....). }\end{array}$ & $\begin{array}{l}\text { In order to make the paper interesting to a wider } \\
\text { audience, terminology has been used which is } \\
\text { less discipline-specific (jargonised) and you see } \\
\text { nowhere where this has compromised the } \\
\text { understanding. } \\
\text { Since Reviewer } 2 \text { found the manuscript to be } \\
\text { "Excellent manuscript - one of the better ones I } \\
\text { have read. Very difficult to find even a minor } \\
\text { change. Good references. Beautifully written" - } \\
\text { and it is impossible to "satisfy" both reviewers as } \\
\text { the comments on our writing are contradictory, } \\
\text { we opt to leave our writing style unchanged. }\end{array}$ \\
\hline
\end{tabular}

